\title{
Oncogenic roles of Bmi1 and its therapeutic inhibition by histone deacetylase inhibitor in tongue cancer
}

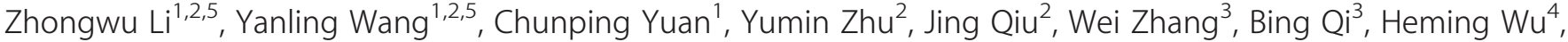 \\ Jinhai $\mathrm{Ye}^{4}$, Hongbing Jiang ${ }^{4}$, Jianrong Yang ${ }^{4}$ and Jie Cheng ${ }^{1,4}$
}

The polycomb complex protein Bmi1 (B lymphoma Mo-MLV insertion region 1 homolog) mediates epigenetic transcriptional silencing by modifying chromatin structure and is critical for stem cell homeostasis and tumorigenesis. Bmi1 is frequently overexpressed in human malignancies and therefore has key diagnostic and prognostic significance, and holds potential as a therapeutic target. Here we sought to characterize the expression patterns and oncogenic roles of Bmi1 in tongue squamous cell carcinoma and to determine the anticancer effects of histone deacetylase inhibitors (HDACis) via Bmi1 inhibition against tongue cancer. Our data revealed that Bmi1 was aberrantly overexpressed in a significant portion of tongue cancers. Elevated Bmi1 is associated with cervical node metastasis, $\mathrm{Ki}-67$ abundance and reduced overall survival, and also serves as an independent prognostic factor for patient outcomes. Short-hairpin RNA-mediated Bmi1 knockdown inhibited cell proliferation and migration, induced cell apoptosis and senescence, reduced colony formation and $\mathrm{CD} 44^{+} \mathrm{CD}_{133^{+}}$sub-population as well as enhanced cisplatin chemosensitivity, presumably by modulation of $p 16$, p14 and E-cadherin. Moreover, HDACi chemicals Trichostatin A (TSA) and sodium butyrate (NaB) potently inhibited Bmi1 and triggered similar phenotypic changes reminiscent of Bmi1 silencing, although TSA treatment seemed paradoxically to induce some epithelial-mesenchymal transition-like changes in tongue cancer cells. Importantly, NaB-induced antitumor effects were partially attenuated by enforced Bmi1 overexpression in vitro. Genetic Bmi1 silencing and pharmacological inhibition of Bmi1 by $\mathrm{NaB}$ treatment significantly impaired tumor growth in a tongue cancer xenograft model. Taken together, our results indicate that Bmi1 serves as a key driver and biomarker with multiple oncogenic functions underlying tongue tumorigenesis. Selected appropriate HDACi compounds like NaB may represent novel therapeutic agents against tongue cancer.

Laboratory Investigation (2014) 94, 1431-1445; doi:10.1038/labinvest.2014.123; published online 6 October 2014

Oral cancer is one of the most common cancers worldwide, approximately accounting for $3 \%$ of all malignancies in both sexes. It is widely represented as a heterogeneous tumor with aggressive phenotypes and behaviors. The major etiological risks for this malignancy include smoking and alcohol consumption and human papillomavirus infection. ${ }^{1}$ The overwhelming majority of oral cancers arises from tongue and is pathologically identified as squamous cell carcinoma (SCC). ${ }^{2}$ Despite tremendous advancement in multimodal therapies against oral cancers over the past decades, the overall 5-year survival rate with these devastating diseases, especially those with advanced diseases, has not been markedly improved. ${ }^{3}$ Local relapse and cervical lymph node metastasis are recognized as the most prevalent factors affecting patients' survival. Although many oncogenes and tumor suppressors have been identified as key factors underlying oral tumorigenesis, however, no optimal and commonly accepted biomarkers have been established to facilitate disease diagnosis, treatment selection and prognostic prediction. ${ }^{4}$ Thus, these facts reflect the aggressive nature of oral cancer and therapeutic challenge for clinicians. Further identification and verification of new biomarkers and therapeutic targets for oral SCC especially the tongue SCC (TSCC) are paramount and urgent to optimize diagnosis and treatment strategies for this malignancy.

Polycomb group proteins are critical transcriptional repressors that epigenetically modify chromatin and govern cell fate decision, stem cell self-renewal and cancer development. ${ }^{5}$

\footnotetext{
${ }^{1}$ Head Neck Cancer Center, Institute of Stomatology, Nanjing Medical University, Jiangsu, China; ${ }^{2}$ Jiangsu Key Laboratory of Oral Disease, Nanjing, China; ${ }^{3}$ Department of Oral Pathology, Nanjing, China and ${ }^{4}$ Department of Oral and Maxillofacial Surgery Affiliated Stomatological Hospital, Nanjing Medical University, Jiangsu, China Correspondence: Dr J Cheng or Dr J Yang, Head Neck Cancer Center, Institute of Stomatology, Nanjing Medical University, 136 Hanzhong Road, Nanjing, China. E-mail: leonardo_cheng@163.com or cj992118@yahoo.com

${ }^{5}$ These two authors contributed equally to this work.

Received 16 March 2014; revised 31 July 2014; accepted 1 August 2014
} 
B lymphoma Mo-MLV insertion region 1 homolog (Bmil) is the core member of the polycomb repressive complex 1 (PRC1) required for monoubiquitination of histone 2A, usually functions as an epigenetic silencer of many target genes such as Ink4a-arf locus. ${ }^{6}$ Bmil-mediated chromatin silencing has been found to be involved in diverse fundamental cellular processes, such as cell proliferation, apoptosis, senescence, epithelial-mesenchymal transition (EMT) and stem cell maintenance. ${ }^{7,8}$ There is increasing evidence that aberrant overexpression of Bmil is associated with multiple human malignancies such as myeloid leukemia, lung cancer, colorectal and breast cancer, and head neck cancer. Furthermore, its overexpression often correlates with advanced stages, aggressive clinicopathological behavior, therapeutic resistance and poor prognosis in these cancers. ${ }^{9-12}$ Enforced overexpression of Bmil promoted malignant transformation, cancer cell proliferation, EMT and metastatic spreading, whereas its depletion inhibited cell proliferation, migration and invasion and induced cell apoptosis and senescence both in vitro and in vivo. ${ }^{13-15}$ Noticeably, Bmil has critical and indispensable roles in maintaining the self-renewal capacity of normal and malignant cancer stem cells, which the latter is increasingly recognized to largely account for cancer initiation and progression, therapeutic resistance and disease relapse.,16,17 A myriad of direct or indirect target genes including p16, p14 and E-cadherin are partially responsible for the essential oncogenic roles of Bmil in diverse cancer contexts. ${ }^{6,8,18}$ These findings have firmly established that Bmil is an important bona fide driver with pleiotropic oncogenic roles during tumorigenesis, thus leading to the hypothesis that blocking Bmil expression/activity and its downstream signaling cascade represents a promising strategy for novel anticancer treatment. Indeed, several reports have shown that genetic silencing and pharmacologic inhibition of Bmil induced cell proliferation arrest, apoptosis, senescence, and increased susceptibility to chemotherapeutic agents, ultimately impaired cancer progression. ${ }^{19}$ More recently, Bmil has been identified as an indispensable factor to maintain the tumor-seeding abilities of colorectal cancerinitiating cells and targeting Bmil with a small-molecule inhibitor resulted in colorectal cancer-initiating cells loss with long-term and irreversible impairment of tumor growth. ${ }^{20}$ Thus, these findings support the notion that targeting Bmil may be an attractive and plausible way to eradicate cancers as a novel therapeutic strategy.

Recently, the histone deacetylase inhibitors (HDACis) have attracted much attention as novel and promising epigenetic therapeutic agents, mainly due to their capacities to induce growth inhibition, cell apoptosis and premature senescence, thereby achieving significant anticancer effects in multiple cancer cells and preclinical animal models. ${ }^{21}$ The primary targets of HDACi are histone deacetylases with varied potency and specificity, however, the detailed mechanisms behind remain incompletely known and probably involve multiple molecular targets depending on cellular and developmental contexts. ${ }^{22}$ Intriguingly, Bmil has been identified as a novel transcriptional target of HDACi and was successfully inhibited in human breast cancer and acute myeloid leukemia cells via pharmacological approach. Three canonical HDACi chemical compounds including sodium butyrate (NaB), valproic acid and Trichostatin A (TSA) have capacities to downregulate Bmil and derepressed its downstream targets, which are known to be silenced by Bmi1. ${ }^{23-25}$ Collectively, these results raise the possibility that therapeutic targeting Bmil by HDACi may hold potentials as a novel anticancer strategy when used as single agent or in combination with current therapeutic agents.

Accumulating evidence has indicated that Bmil serves as an essential regulator during the initiation and progression of head neck cancers. ${ }^{26-28}$ Overexpression of Bmil significantly associated with malignant transformation of oral precancerous lesions, EMT of oral epithelial cells and cancer stem cell maintenance. ${ }^{29,30}$ Moreover, elevated Bmil correlated with aggressive features and unfavorable patients' survival., ${ }^{9,26,27}$ However, the in-depth investigations into the expression pattern of Bmil and associated molecular mechanisms underlying TSCC development remain to be further clarified. Intriguingly, therapeutic efficiency of targeting Bmil by HDACi compounds in tongue cancer cells remains unexplored. Therefore, in this study, we first examined the Bmil expression and its clinicopathological significance in tongue cancer cell lines and clinical samples. Then, the biological roles responsible for Bmil in tongue cancer progression were identified by loss-of-function assays via both short-hairpin RNA (shRNA)-mediated genetic and HDACi-mediated pharmacological approaches in vitro and in vivo.

\section{MATERIALS AND METHODS \\ Tongue Cancer Cell Lines and Chemical Reagents}

A panel of human TSCC cell lines HN4, HN6, HN12, Tca8113, Cal27, SCC9 and SCC25 were used here. The HN cells were obtained from National Institutes of Health. Tca8113 was previously established at Shanghai Jiaotong University (a generous gift from Professor Wantao Chen). ${ }^{31}$ The Cal27, SCC9 and SCC25 cells were purchased from American Type Culture Collection (ATCC). Cancerous cell lines were grown in DMEM (Invitrogen) supplemented with $10 \%$ FBS (Gibco) and 100 units/ml penicillin and streptomycin, and maintained in a humidified incubator with $5 \% \mathrm{CO}_{2}$ at $37^{\circ} \mathrm{C}$. The HDACis TSA and $\mathrm{NaB}$ were purchased from Sigma Aldrich (category number: T8552, B5887) and dissolved in DMSO or PBS as stocking solutions and diluted with culture medium upon addition into cells. Cells were treated with diverse concentrations of TSA or NaB for the indicated times. For chemotherapy sensitivity assay in vitro, shRNA-mediated Bmil-silencing cells were further treated with cisplatin (Sigma Aldrich, category number: P4394, $2.5 \mu \mathrm{g} / \mathrm{ml}$ ) or these cancerous cells were exposed with cisplatin alone or in combination with TSA or $\mathrm{NaB}$ for the indicated times. For in vitro cellular rescue experiments, 
following pretreated with $\mathrm{NaB}(2 \mu \mathrm{M})$ for $48 \mathrm{~h}$, the cells were further transiently transfected with pcDNA3-Bmil plasmid (gifted from Professor Muh-Hwa Yang, National Yang-Ming University, Taiwan $)^{8}$ for another $48 \mathrm{~h}$ and then subjected to further experiments.

\section{Bmi1 shRNA Plasmids Construction and In Vitro Transfection}

Two shRNA interference plasmids targeting different regions of human Bmil were designed and purchased from Shanghai GenePharma. The efficiency and specificity of these shRNA sequences had been verified previously. ${ }^{8,32}$ The knockdown efficiency of each shRNA construct was further confirmed by in vitro delivery to cells using lipofectamine 2000 (Invitrogen) according to the manufacturer's recommendations. After transfection for 24 or $48 \mathrm{~h}$, the cells were harvested for the further experiments.

\section{Cell Immunofluorescence and Imaging}

The cancerous cells were seeded and grown on glass coverslips $24 \mathrm{~h}$ before experiment. After fixed with $4 \%$ paraformaldehyde-PBS for $15 \mathrm{~min}$, cells were then permeabilized in $0.1 \%$ Triton X-100 in PBS and sequentially blocked with $3 \%$ bovine serum albumin for $30 \mathrm{~min}$. Following the overnight incubation with primary antibodies specific for Bmi1 (Cell Signaling, \# 6964, 1:200 dilution), E-cadherin (Cell Signaling, \# 3195, 1:250 dilution), these cells were further incubated with appropriate secondary antibodies and cytoskeleton actin staining. Immunofluorescence was visualized under a Zeiss fluorescence microscope and image captured.

\section{RNA Extraction and Real-Time RT-PCR}

Total RNA was extracted from cells using Trizol reagent (Invitrogen) and then reversely transcribed into first strand cDNA using PrimeScript ${ }^{\mathrm{TM}}$ RT reagent kit (Takara). The generated cDNA was used for real-time PCR reaction using SYBR Premix Ex Taq ${ }^{\mathrm{TM}}$ kit (Takara) following the supplier's instructions. The gene-specific primers for human Bmil, Ezh2, p16, p14, E-cadherin, Vimentin, CD44, CD133 and GAPDH were purchased commercially (Invitrogen). Relative mRNA expression of each gene as compared with internal control GAPDH was quantified using comparative CT method.

\section{Western Blot Analysis}

The cells with $80-90 \%$ confluence in culture flasks were lysed in ice-cold buffer containing protease inhibitor cocktail (Roche) as we reported before. ${ }^{33}$ Equal amounts of protein samples were loaded and separated by $8-12 \%$ SDS-PAGE and transferred to PVDF membranes (Millipore), which then were blocked by $5 \%$ non-fat dry milk. These blots were incubated at $4{ }^{\circ} \mathrm{C}$ overnight with primary antibodies Bmil, EZH2, p16, cleaved-PARP (Cell Signaling, 1:1000 dilution), E-cadherin, Vimentin (BD Biosciences, 1:2000 dilution) and GAPDH (Santa Cruz, 1:2000 dilution) followed by incubations with secondary antibodies. The relative levels of each protein were quantified with Quantity One software (Bio-Rad).

\section{MTT Assay}

Cell proliferation and viability were monitored by absorbance using MTT assay. Approximately 1000-3000 cells per well were seeded in the 96-well plates. At the indicated timepoints, $5 \mathrm{mg} / \mathrm{ml} \mathrm{MTT} \mathrm{(Sigma)} \mathrm{was} \mathrm{added} \mathrm{to} \mathrm{the} \mathrm{cells} \mathrm{and}$ incubated at $37^{\circ} \mathrm{C}$ for another $4 \mathrm{~h}$. Absorbance at $490 \mathrm{~nm}$ was measured with an automatic enzyme-linked immunosorbent assay reader (BioTek Instruments).

\section{Flow Cytometry Analysis}

Cells were treated with trypsin and resuspended as single-cell suspension. For apoptosis assay, cells were stained with Annexin V: PE Apoptosis Detection Kit (BD Bioscience). For cell surface maker assay and cell sorting, cells were labeled with human fluorochrome-conjugated anti-CD44-APC (BD Pharmingen) and anti-CD133-PE (Miltenyi Biotec) and then sorted by BD FACSVantage flow cytometer. The corresponding immunoglobulins conjugated antibodies were used as isotype controls in each experiment.

\section{In Vitro Cell Migration and Wound-Healing Assay}

Cell migration assay was performed using chambers $(8-\mu \mathrm{m}$ pore size, Corning) in 24-well plates. Forty-eight hours after shRNA transfection, cells were detached and resuspended, then seeded into the upper chambers with medium containing $1 \%$ FBS. Complete medium containing $10 \%$ FBS in the lower chambers served as chemoattractant. The noninvading cells were gently removed with a cotton swab and those migratory cells located on the lower side were stained with crystal violet. The number of migrated cells were counted and averaged in randomly selected 10 fields under microscope. For wound-healing assay, cells were grown into confluent monolayers and scratched using a sterile $200 \mu \mathrm{l}$ pipette. Cell migration was observed at various time-points later by microscopy. Images of 10 scratches per cells were captured during the experiment and compared with Image J software.

\section{Senescence $\beta$-Galactosidase Cell Staining}

Senescence $\beta$-galactosidase cell staining was performed using staining kit purchased from Cell Signaling (\#9860) and performed accordingly. Briefly, cells were fixed in $2 \%$ formaldehyde $/ 0.2 \%$ glutaraldehyde/PBS for $15 \mathrm{~min}$ at room temperature and stained using $\beta$-galactosidase staining solution at $37^{\circ} \mathrm{C}$ overnight. The percentage of SA- $\beta$-galpositive cells was calculated from 10 randomly chosen fields. At least 200 cells were analyzed per experiment.

\section{Colony-Forming Assay}

One thousand shBmil-transfected and control cells or cells pretreated with TSA, $\mathrm{NaB}$ or vehicle were placed into six-well 
plates or dishes and allowed to grow for 2 weeks. The cells were then fixed and stained with crystal violet. The colonies were further visualized under an invert microscope and photographed. Cell aggregations with $>50$ cells were defined as colonies and counted.

\section{TSCC Xenograft Model and NaB Treatment}

All the animal protocols were in accordance with institutional animal welfare guidelines of Nanjing Medical University. Two million Bmil knockdown and control cells (HN4-shBmil, HN4-NC) were injected subcutaneously on the right flank of male nu/nu mice (8-week old). After tumor growth was monitored for 24 consecutive days, the animals were killed and tumor samples were harvested for further analyses. For drug-treatment animal experiments, $1.5 \times 10^{6}$ viable $\mathrm{HN} 4$ cells were inoculated subcutaneously. Four weeks later, these mice bearing tumors were randomly divided into two groups (six mice per group), which were scheduled to receive the following treatments: $150 \mathrm{mg} / \mathrm{kg} \mathrm{NaB}$, once every 2 days by intraperitoneal injection or vehicle (PBS) only in controls for consecutive 12 days. The tumor diameters were measured by calipers every 3 days. Tumor volume was calculated by the formula volume $\left(\mathrm{mm}^{3}\right)=\left(\right.$ length $(\mathrm{mm}) \times$ width $\left.(\mathrm{mm})^{2}\right) \times 0.5$. Tumor weight was also measured upon tumor samples were harvested.

\section{Patients and Tissue Specimens}

A total number of 52 patients with primary TSCC treated at the Department of Oral and Maxillofacial Surgery, Nanjing Medical University from 2001 to 2011 were collected. These patients were diagnosed as primary TSCC without any prior history of chemotherapy or radiotherapy and underwent radical tumor ablation and neck lymph node dissection (elective or therapeutic neck dissection as required) alone. The archived tissue samples were retrieved and hematoxylineosin staining slides for each patient were further analyzed to confirm the previous histological diagnoses based on the established histological criteria. Sixteen samples of normal tongue mucosa were obtained from non-cancer-related surgeries during the same period and histomorphologically verified. All these patients gave written informed consent in line with our institutional guidelines. This study protocol was reviewed and approved by the Research Ethic Committee of Nanjing Medical University.

\section{Histopathological Evaluation and Immunohistochemistry}

Immunohistochemical staining for Bmil and $\mathrm{Ki}-67$ was performed and scored similarly as our previous reports. ${ }^{34,35}$ The immunoreactivity in each slide was assessed independently by two senior oral pathologists without knowledge about the clinical and pathological information. Negative controls (without primary antibody incubation) were included in each staining run. Immunoreactivity was semiquantitatively evaluated on the basis of staining intensity and distribution using the immunoreactive score, which was calculated as intensity score $\times$ proportion score. The immunoreactivity of each slide was divided into three groups based on the final score: 0, negative; $1-4$, low expression; 4-12, high expression.

\section{Statistical Analysis}

All quantitative data in this study was shown as mean \pm s.d. of two or three independent experiments and compared with Student's $t$-test or ANOVA unless otherwise specified. The associations between Bmil/Ki-67 expression and various clinicopathological parameters were evaluated using Fisher's exact test or $\chi^{2}$-test as indicated. The overall survival rate was estimated using Kaplan-Meier method and compared with log-rank test. The prognostic analyses were performed by univariate and multivariate Cox regression models to determine the clinicopathological variables with overall survival. $P$-values $<0.05$ (two-sided) were considered statistically significant. All statistical analyses were performed using GraphPad Prism 5 or SPSS 18.0 software.

\section{RESULTS}

\section{Bmi1 is Aberrantly Overexpressed in TSCC Cell Lines and Clinical Specimens}

To initially explore the Bmil expression in TSCC, we first evaluated both mRNA and protein levels of Bmil in a panel of TSCC cell lines as compared with normal tongue mucosa. As shown in Figure 1a, Bmil mRNA levels in the cancerous cells except the Tca8113 were significantly higher than that in normal mucosa as assessed by real-time RT-PCR assay. The amounts of Bmil mRNA in Cal27, SCC9, SCC25, HN4, HN6, HN12 were elevated approximately $3.45,3.71,3.57$, $8.42,5.82$ and 6.21-folds $(P<0.01)$, respectively. The following western blotting results further confirmed the significantly upregulated Bmil expression in the TSCC cells lines except Tca8113 (Figure 1b). To characterize the subcellular distribution of Bmil in tongue cancer cells, cellular immunofluorescence was performed in three selected cell lines. As shown in Figure 1c, Bmil was readily detected and mainly identified in nucleus in these cancer cell lines examined. To further examine Bmil expression in clinical specimens, we next evaluated the expression patterns of Bmil by immunohistochemical staining in a retrospective cohort of 52 primary TSCC samples. In accordance with our immunohistochemistry scoring method, Bmil expression patterns in TSCC and normal tongue mucosa were shown in Figure 1e. Bmil abundance in these TSCC specimens were graded as low (16) or high expression group (36), whereas its expression levels in normal counterparts were divided into negative (4), low (9) and high (3) group, a clear indicative of aberrant overexpression of Bmil in a major fraction of TSCC samples $(P<0.01)$. A representative labeling of Bmil in TSCC and normal tongue mucosa was shown in Figure 1d. Consistent with the chromatin-modifying roles of Bmil in nucleus, high Bmil expression was identified mainly in 

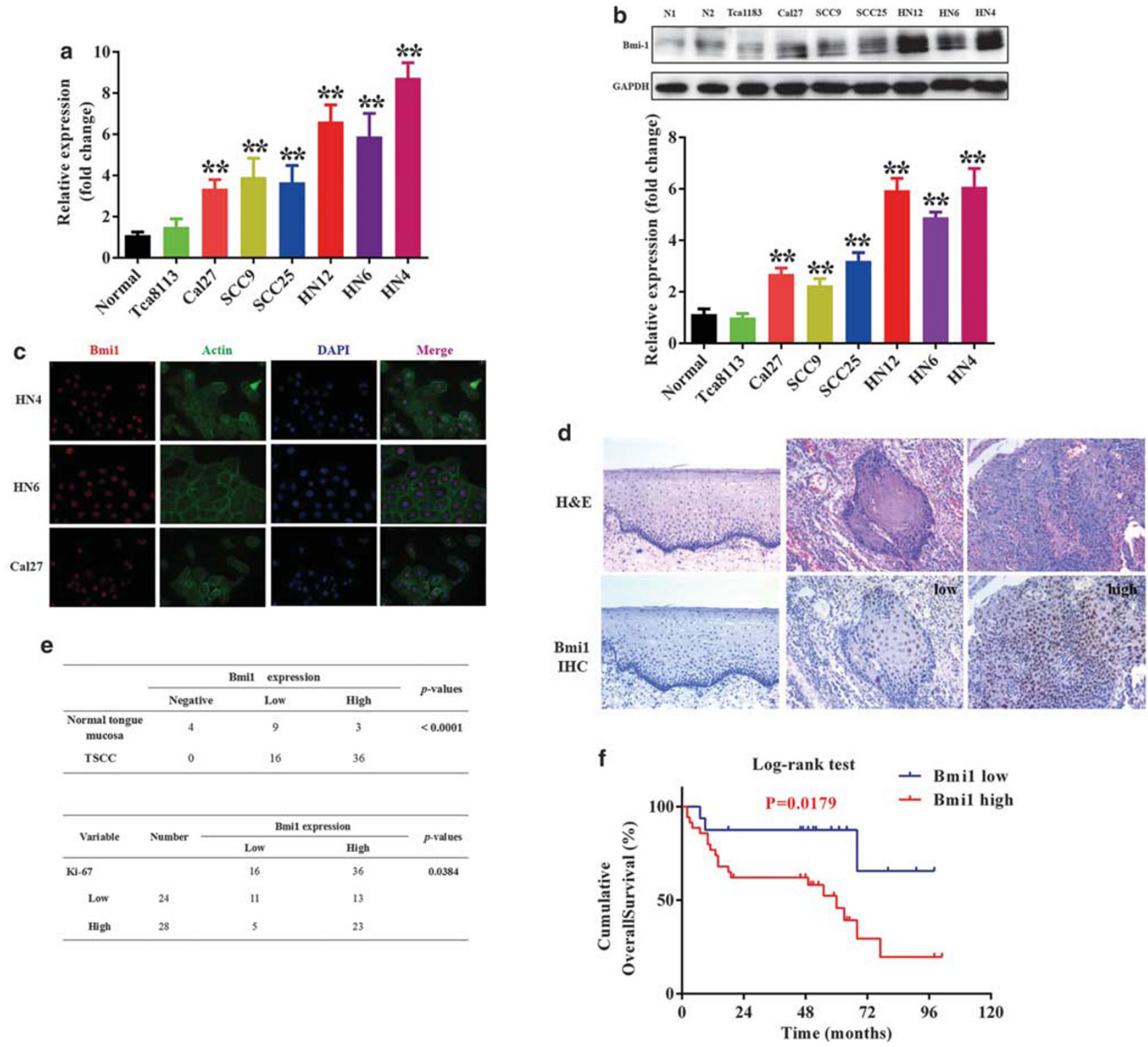

Figure 1 Overexpression of Bmi1 and its prognostic significance in TSCC. (a) Bmi1 mRNA levels were measured by real-time RT-PCR in seven TSCC cell lines as compared with normal tongue mucosa $(n=3)$. (b) Bmi1 protein levels were determined by western blot (WB) in TSCC lines as compared with normal tongue mucosa. Representative images of WB are shown. (c) Localization of Bmi1 (mainly in nucleus) was identified by immunofluorescence staining in tongue cancer cells. Representative immunofluorescence images are shown. (d) Bmi1 expression in human TSCC specimens was evaluated by immunohistochemical staining $(\times 200)$. Left to right: negative expression in normal tongue mucosa; low expression in TSCC; high expression in TSCC. Upper panel: HE staining; Lower panel: IHC staining. (e) Expression patterns of Bmi1 in human TSCC samples and correlation between Bmi1 and Ki-67 were statistically determined. (f) Overall survival analysis of patients with high or low expression of Bmi1 was estimated by Kaplan-Meier method and compared with log-rank test. Data shown here are mean \pm s.d. from three independent experiments. ${ }^{* *} P<0.01$, ANOVA analysis.

nucleus but rarely in cytoplasm in cancer cells. Collectively, these data indicate that Bmil is aberrantly overexpressed in a significant fraction of tongue cancers.

\section{Overexpression of Bmi1 Associates with Cervical Nodes Metastasis, Ki-67 Expression and Poor Prognosis of TSCC}

To dissect the clinical relevance of Bmil overexpression in tongue cancers, we next set out to identify potential associations between Bmil expression and patients' clinicopathological parameters. The detailed relationships between Bmil status and several clinicopathological variables from 52 patients were shown in Table 1. In brief, 28 male and 24 female patients were enrolled with mean age 53.1 years (26-76 years). The follow-up period ranged from 2 to 102 months with average 43.8 months. There were no significant correlations between Bmil expression with patients' age, gender, tumor size, local invasion, pathological grade and 
Table 1 Expression of Bmi1 and its associations with clinicopathological parameters in 52 TSCC

\begin{tabular}{|c|c|c|c|c|}
\hline \multirow[b]{2}{*}{ Parameter } & \multirow[b]{2}{*}{ Patient no. } & \multicolumn{2}{|c|}{ Bmi1 } & \multirow[b]{2}{*}{$P$-value } \\
\hline & & Low & High & \\
\hline Gender & 52 & & & \\
\hline Male & 28 & 12 & 16 & 0.0695 \\
\hline Female & 24 & 4 & 20 & \\
\hline \multicolumn{5}{|l|}{ Age } \\
\hline$\leq 60$ & 35 & 12 & 23 & 0.5316 \\
\hline$>60$ & 17 & 4 & 13 & \\
\hline \multicolumn{5}{|l|}{ Tumor size } \\
\hline $\mathrm{T} 1-\mathrm{T} 2$ & 36 & 10 & 26 & 0.5269 \\
\hline T3-T4 & 16 & 6 & 10 & \\
\hline \multicolumn{5}{|c|}{ Pathological grade } \\
\hline I & 20 & 8 & 12 & 0.3559 \\
\hline$\|-1\|$ & 32 & 8 & 24 & \\
\hline \multicolumn{5}{|c|}{ Local invasion } \\
\hline No & 22 & 6 & 16 & 0.7646 \\
\hline Yes & 30 & 10 & 20 & \\
\hline \multicolumn{5}{|c|}{ Cervical nodal metastasis } \\
\hline$N(0)$ & 25 & 4 & 21 & 0.0367 \\
\hline $\mathrm{N}(+)$ & 27 & 12 & 15 & \\
\hline \multicolumn{5}{|c|}{ Clinical stage } \\
\hline$|-| \mid$ & 22 & 8 & 14 & 0.5482 \\
\hline III-IV & 30 & 8 & 22 & \\
\hline
\end{tabular}

clinical stage. Noticeably, significant association between Bmil abundance with cervical nodes metastasis was found with $P$-values 0.0367 . Given the putative pro-proliferative roles of Bmil during cancer progression, we determined whether a positive correlation between Bmil and Ki-67 existed in TSCC. The expression of canonic cell proliferation marker Ki-67 was evaluated by immunohistochemical staining in the same patient cohort. Indeed, as shown in Figure 1e, Bmil expression was found to be significantly associated with $\mathrm{Ki}-67(P=0.0384)$ in these patients analyzed.

To further reveal clinical significance of Bmil expression in TSCC patients' prognosis, we then evaluated the correlation between Bmil expression and clinical outcomes. At the time of the last follow-up, 27 of 52 (51.9\%) patients were alive and disease-free, 5 (9.6\%) patients with locoregional recurrence and/or cervical nodal metastases, $20(38.5 \%)$ patients died because of local recurrence, metastases or other unrelated diseases. In a Kaplan-Meier survival analysis, as shown in Figure 1f, high Bmil expression in TSCC was significantly associated with reduced overall survival (log-rank, $P=$ 0.0179), suggesting that Bmil overexpression associated with adverse prognosis.

To assess whether Bmil expression can be identified as a prognostic predictor for TSCC patients, both univariate and multivariate survival analyses (Cox proportional hazards regression model) were performed. In the univariate survival analysis, Bmil expression and cervical nodal metastasis significantly associated with overall survival $(P=0.002,0.034$, respectively), whereas other clinicopathological variables did not reach the statistical significance as indicated in Table 2 . To rule out confounding factors, multivariate survival analysis was carried out with relevant covariates. In this Cox regression model, together with cervical nodal metastasis $(P=0.023)$, Bmil expression status was found to be an independent prognostic marker for the overall survival of TSCC patients $(P=0.010)$. Together, these data reveal that Bmil is an important diagnostic and prognostic biomarker with incompletely recognized oncogenic functions in tongue cancer.

\section{Bmi1 Knockdown Inhibits Cell Proliferation and Migration, and Induces Cell Apoptosis in Tongue Cancer Cell}

These above findings from our studies and others have strongly suggested that Bmil may be a key oncogenic driver during tongue tumorigenesis. ${ }^{11,27}$ However, the detailed pathological roles of Bmil underlying this process have not been completely appreciated, which prompted us to further unravel the oncogenic functions of Bmil and relevant mechanisms. The shRNA-mediated knockdown strategy was exploited to delineate the resulting phenotype changes after endogenous Bmil was specifically inhibited in vitro. As shown in Figures 2a and b, both mRNA and protein of Bmil were remarkably reduced following the shBmil plasmids transfection into cells as compared with nonspecific control. The shBmil plasmid with more knockdown potency (shBmil-1 for HN4 cells and shBmil-2 for HN12 cells, respectively) was identified and utilized in the following experiments. In order to further confirm the Bmil knockdown in vitro, the expression changes of two downstream targets of Bmil, p16 and p14, which were normally silenced by Bmil were determined following Bmil knockdown. Our data from real-time RT-PCR assay indicated that they were derepressed and significantly upregulated in HN4 and HN12 cells when endogenous Bmil was depleted (Supplementary Figure 1), thus displaying the potency and specificity of the shBmil-mediated knockdown. Subsequently, the relevant phenotype changes of cells after Bmil silencing were further examined in detail. As shown in Figure 2c, Bmil depletion 
Table 2 Univariate and multivariate survival analyses (proportional hazards method) for patients with TSCC

\begin{tabular}{|c|c|c|c|c|c|c|}
\hline \multirow[b]{2}{*}{ Variable } & \multicolumn{2}{|c|}{ Univariate survival analysis } & \multirow[b]{2}{*}{$P$-value } & \multicolumn{2}{|c|}{ Multivariate survival analysis } & \multirow[b]{2}{*}{$P$-value } \\
\hline & Hazard ratio & $95 \% \mathrm{Cl}$ & & Hazard ratio & $95 \% \mathrm{Cl}$ & \\
\hline Gender (male, female) & 1.465 & $0.611-3.512$ & 0.392 & 1.414 & $0.430-4.653$ & 0.569 \\
\hline Age $(\leq 60,>60)$ & 0.829 & $0.325-2.110$ & 0.694 & 2.257 & $0.779-6.540$ & 0.134 \\
\hline Tumor size (T1-T2, T3-T4) & 1.449 & $0.582-3.608$ & 0.425 & 1.525 & $0.221-10.503$ & 0.747 \\
\hline Local invasion (no, yes) & 1.429 & $0.601-3.397$ & 0.419 & 4.055 & $0.909-18.087$ & 0.067 \\
\hline Cervical nodal metastasis $(\mathrm{N} 0, \mathrm{~N}+$ ) & 4.068 & $1.639-10.096$ & 0.002 & 4.539 & $1.231-16.733$ & 0.023 \\
\hline Clinical stage (I-II, III-IV) & 1.934 & $0.805-4.650$ & 0.140 & 1.525 & $0.221-10.503$ & 0.668 \\
\hline Bmi1 expression (low, high) & 4.871 & $1.131-20.982$ & 0.034 & 9.428 & $1.705-52.151$ & 0.010 \\
\hline
\end{tabular}

The numbers in bold indicate statistical significace.

a

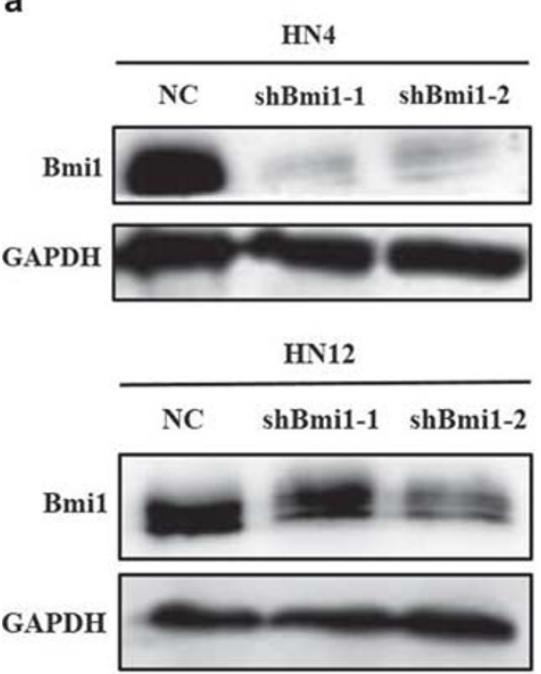

d

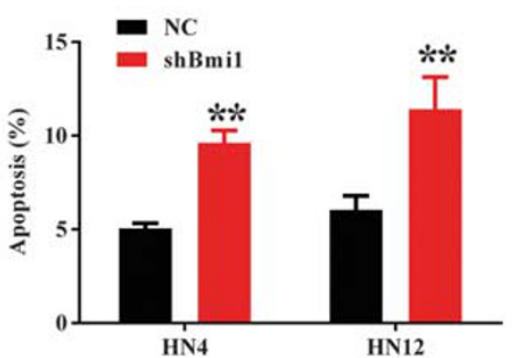

b

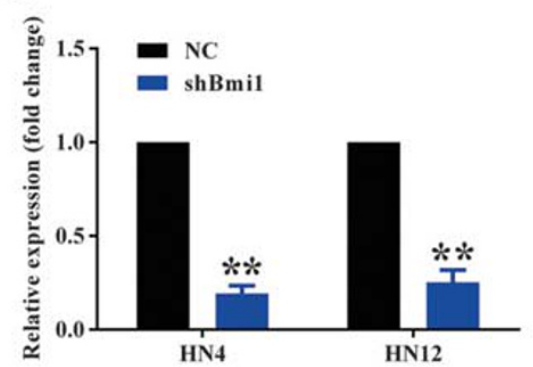

\section{e}

HN12

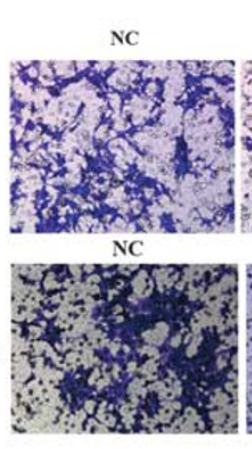

shBmil-1

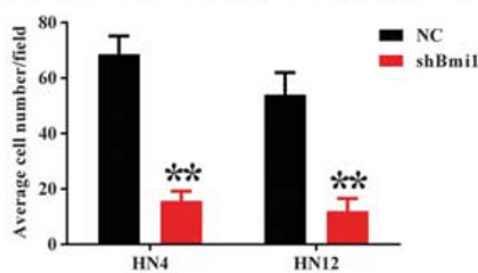

c
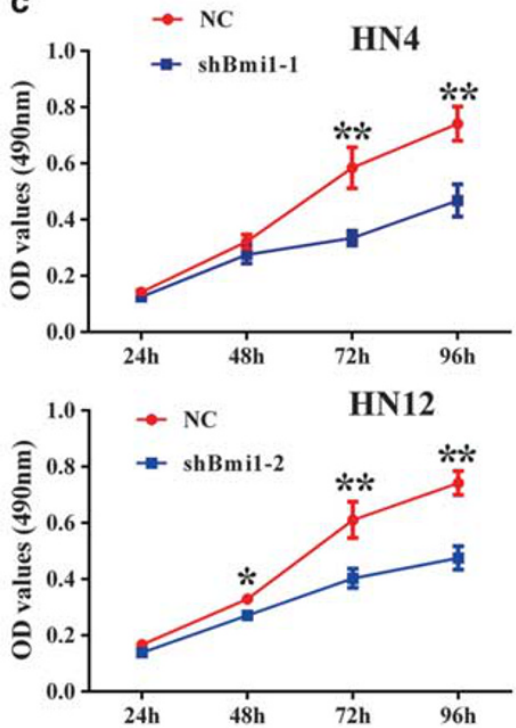

f

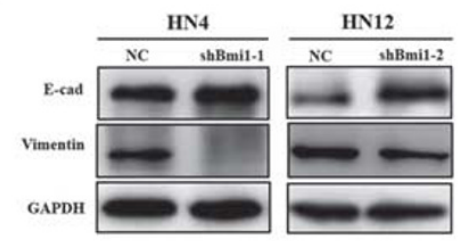

Figure 2 Bmi1 knockdown inhibits cell proliferation and migration, and triggers cell apoptosis in tongue cancer cells. (a) Endogenous Bmi1 was efficiently silenced by shBmi1 in two tongue cancer cell lines. Representative images of WB are shown. (b) The mRNA levels of Bmi1 were significantly decreased following Bmi1 knockdown. (c) Cell proliferation was remarkably suppressed when endogenous Bmi1 was silenced as measured by MTT assay. (d) Increased percentages of cell undergoing apoptosis were evident in shBmi1-transfected cells as assayed by Annexin V-PI double staining. (e) The migration ability was significantly reduced in shBmi1-treated cells in relative to control. The numbers of migrated cells were calculated in randomly selected 10 fields under microscope and then averaged (lower panel). (f) The abundances of E-cadherin and Vimentin were measured by WB following endogenous Bmi1 knockdown. Representative images are shown. Data shown here are mean \pm s.d. from three independent experiments, ${ }^{*} P<0.05,{ }^{* *} P<0.01$, Student's $t$-test. 
resulted in impaired cell proliferation in both cells as evidenced by the facts that shBmil-transfected HN4 and HN12 displayed much lower cell viability at 72 and $96 \mathrm{~h}$ after transfection as compared with control, although the inhibitory effects were not much obvious at 24 and $48 \mathrm{~h}$. In addition, the Annexin V and PI double staining data indicated that $48 \mathrm{~h}$ after transfection, the percentages of cells undergoing apoptosis were higher in shBmil-treated cells when compared with controls (HN4 4.96\% vs 9.68\%; HN12 $5.32 \%$ vs $11.25 \% ; P<0.01$; Figure $2 \mathrm{~d}$ ), suggesting that Bmi1 silencing induced cell apoptosis in tongue cancer cells. Moreover, shBmil-transfected cells displayed impaired migration capacity as shown in Figure 2e. In line with this, gain of E-cadherin and loss of Vimentin follow Bmil knockdown were detected in both cell lines, which presumably accounted for the impaired immigration (Figure 2f). Collectively, these results provide evidence that Bmil is implicated in cell proliferation, apoptosis and migration in tongue cancer cell.

\section{Bmi1 Knockdown Reduces Cell Cloning Potential, Percentage of CD44 ${ }^{+}$CD133 ${ }^{+}$Cell Sub-Population, Triggers Cell Senescence and Enhances Cisplatin Chemosensitivity}

Given the essential roles of Bmil in cancer initiation and progression, in particular cancer stem cell maintenance and function, senescence and chemoresistance, ${ }^{17,36}$ we then asked whether Bmil knockdown affected these properties in tongue cancer cells. First, the colony-forming assay was performed to evaluate the roles of Bmil in the colony-forming efficiency, which is a surrogate readout of stem cell abundance. The results indicated that the numbers of colony were much fewer in shBmil-treated cells than those in control cells $(P<0.05$; Figure 3a). In addition, the sizes of colonies were also markedly smaller in shBmil-treated cells as compared with control. Then, we next sought to measure Bmil in the CD44 and CD133 double-positive cell sub-population, which enriched putative cancer stem cells by fluorescent-activated cell sorting. ${ }^{37,38}$ Following cell sorting, these cell fractions with both $\mathrm{CD} 44$ and $\mathrm{CD} 133$ positive and negative were subjected to western blot assay. Significantly elevated Bmi1 was observed in $\mathrm{CD} 44^{+} \mathrm{CD} 133^{+}$fraction as compared with $\mathrm{CD} 44^{-} \mathrm{CD} 133^{-}$fraction and unsorted parental population (Supplementary Figure 2). Notably, the percentage of $\mathrm{CD} 44^{+} \mathrm{CD} 133^{+}$cell fraction decreased significantly from 20.8 to $15.9 \%$ in HN4 and 10.2 to $3.17 \%$ in HN12 following Bmil knockdown as shown in Figure 3b. These two cell surface markers CD44 and CD133, commonly used for cancer stem cell identification and enrichment in multiple cancers, were significantly downregulated in cells with Bmi1 silencing (Supplementary Figure 3). These data suggested important roles of Bmil in maintaining $\mathrm{CD} 44^{+} \mathrm{CD} 133^{+}$ sub-population in tongue cancer. As shown in Figure 3c, increased SA- $\beta$-gal staining positive cells were observed in cells transfected with shBmil as relative to control $(P<0.01)$, indicating Bmil knockdown triggered cells to undergo senescence. As the key roles of Bmil-mediated p16 expression during cell senescence, ${ }^{39}$ p16 mRNA and protein were both significantly elevated after Bmil silencing, further confirming the Bmi1-p16 involvement in regulation of tongue cancer cell senescence (Figure 3d and Supplementary Figure 1). Previous reports have offered clues that aberrantly overexpression of Bmil associated with chemoresistance and its depletion enhanced chemosensitivity in multiple cancers. ${ }^{36}$ Then, we wondered whether Bmil knockdown can enhance antitumor activities with the commonly used anticancer drug cisplatin. Not surprisingly, cell viability was significantly impaired when cells were treated with cisplatin or shBmil alone as measured by MTT assay. Remarkably, cell viability and proliferation were more significantly reduced in shBmil cells treated with cisplatin in comparison with those cells with cisplatin (Figure 3e). Furthermore, the percentage of apoptotic cells was much higher in shBmil cells with cisplatin incubation than that in cells with cisplatin only (data not shown). Together, these findings suggest that Bmil is involved in cancer stem cell maintenance, cell senescence and chemotherapeutic sensitivity in tongue cancer cell.

\section{HDACi Inhibits Bmi1 Expression in Tongue Cancer Cells}

Several lines of evidence have indicated that the members of PRC such as Bmil are identified as transcriptional targets of HDACi and several HDACis have capacities to repress Bmil and derepressed its downstream targets in various cancer cells. ${ }^{23-25}$ Then we sought to confirm whether HDACis were capable to repress Bmil expression in tongue cancer cells. Two HDACis, TSA and NaB, were used to evaluate their effects on Bmil abundance. HN4 cells were incubated with various concentrations of TSA $(0-400 \mathrm{nM})$ and $\mathrm{NaB}$ $(0-4 \mu \mathrm{M})$ for varying time courses. As shown in Figures $4 \mathrm{a}$ and $\mathrm{b}, \mathrm{TSA}$ and $\mathrm{NaB}$ exposure induced a time-dependent and dose-dependent decrease of Bmil protein in $\mathrm{HN} 4$ cells. In addition, another key member of polycomb complex EZH2 was also inhibited by both TSA and $\mathrm{NaB}$ in vitro (Figure 4c). Moreover, TSA and $\mathrm{NaB}$ treatment significantly inhibited mRNA levels of Bmil and EZH2, and derepressed p16 simultaneously (Figure 4d). Taken together, these data indicate that TSA and $\mathrm{NaB}$ have capacities to inhibit Bmil expression in tongue cancer cell.

\section{HDACi-Induced Bmi1 Depletion Phenocopies shRNA-Mediated Bmi1 Silencing In Vitro}

We next want to clarify the effects of TSA and NaB on cell phenotypic changes in tongue cancer cells and whether these changes resemble those of Bmil knockdown. In general, the resultant effects induced by TSA and $\mathrm{NaB}$ exposure largely phenocopied the changes following Bmil knockdown in HN4 cells. As displayed in Figures $5 \mathrm{a}-\mathrm{f}$ and Supplementary Figure 4, our results indicate that both TSA and $\mathrm{NaB}$ treatment result in impaired cell proliferation, reduced migration and cell colony formation, more apoptotic and senescence 
a

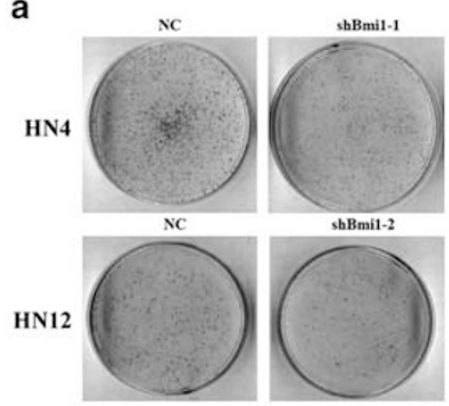

C

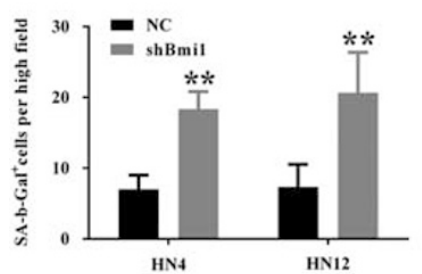

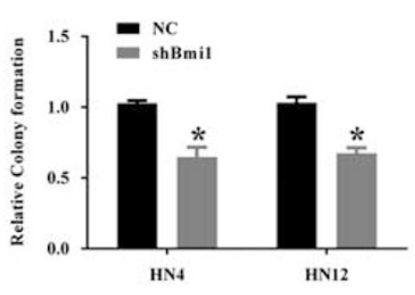

b
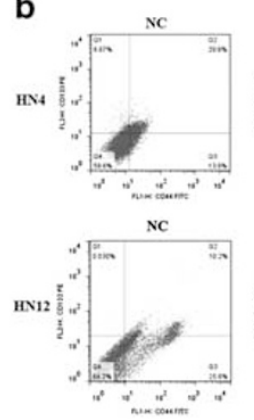

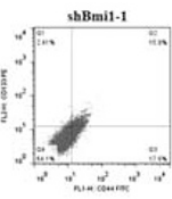

shBmil-2

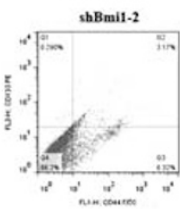

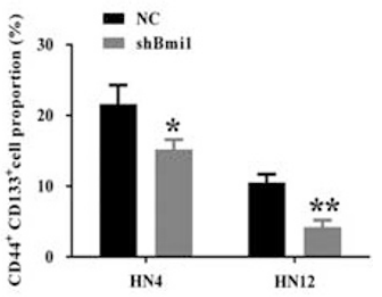

d

e
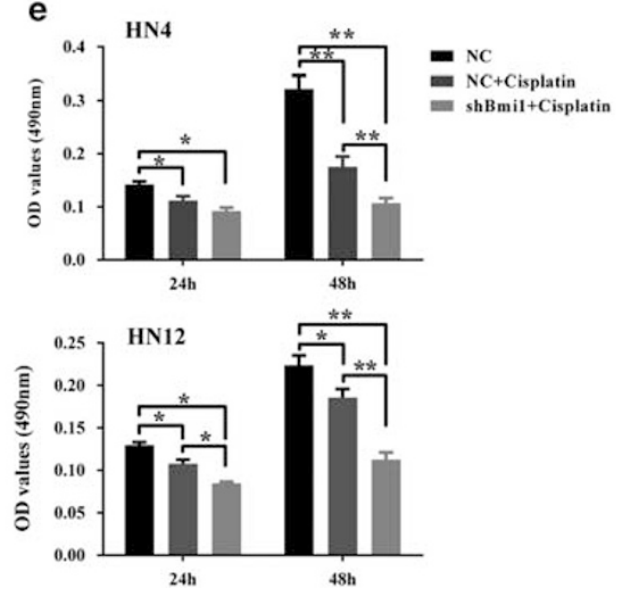

Figure 3 Bmi1 knockdown reduces colony formation, $\mathrm{CD}_{4} 4^{+} \mathrm{CD}_{133^{+}}$sub-population, triggers cell senescence, and enhance cisplatin chemosensitivity in tongue cancer cells. (a) The colony formation efficiency was pronouncedly reduced in shBmi1 cells as compared with control. (b) The percentages of $\mathrm{CD}_{4}{ }^{+} \mathrm{CD}_{133^{+}}$sub-population enriched with putative cancer stem cells were decreased after Bmi1 knockdown as measured by FACS. (c) The proportion of cell undergoing senescence was markedly increased following Bmi1 silencing as determined by SA- $\beta$-gal staining. (d) The abundance of p16 as cell senescence regulator was measured by WB assay. Representative images of WB are shown. The same GAPDH blot was used in Figure 3d and Figure $2 \mathrm{f}$ from a representative experiment. (e) Cell proliferation was significantly inhibited in shBmi 1 cells treated by cisplatin $(2.5 \mu \mathrm{g} / \mathrm{ml})$ as assayed by MTT. Data shown here are mean \pm s.d. from three independent experiments, ${ }^{*} P<0.05,{ }^{* *} P<0.01$, Student's $t$-test and ANOVA analyses.

cells, reduced proportion of $\mathrm{CD} 44^{+} \mathrm{CD} 133^{+}$cell fractions and enhanced cisplatin sensitivity, largely resembling the results derived from Bmil silencing in vitro. However, unexpectedly, significant morphological changes were observed in TSA-treated cells, whereas no such morphological changes were detected in NaB-treated cells. As shown in Supplementary Figures 5A and B, TSA-treated cells displayed EMT-like characteristics such as spindle fibroblast-like shape and loss of cell-cell adhesion, whereas NaB-treated cells remained unchanged with typical epithelial morphology. In addition, EMT marker E-cadherin was significantly decreased and Vimentin was remarkably upregulated in TSA-treated HN4 cells, whereas $\mathrm{NaB}$ appeared to induce the opposite changes as E-cadherin gain and Vimentin loss (Supplementary Figures 5B and C). This finding suggested that TSA may have the potential to trigger EMT in tongue cancer cells. To discriminate whether such morphological changes were due to specific cell type or specific HDACi chemicals, we then tested both TSA and NaB in another two cell lines HN6 and Cal27. The data indicated that only TSA treatment can result in EMT-like morphological changes and E-cadherin loss in HN6 cells (Supplementary Figures 5A, C and D) and Cal27 cells (data not shown). As expected, TSA exposure significantly enhanced cell migration, whereas $\mathrm{NaB}$ treatment remarkably impaired cell migration in both HN4 and HN6 cells (Supplementary Figure 5E and data not shown). Taken together, these data reveal that HDACis TSA and NaB have potent anticancer effects in tongue cancer cells. TSA, not $\mathrm{NaB}$, had unexpected potential to induce EMT-like changes in tongue cancer cells.

\section{NaB Induces Anticancer Effects on Tongue Cancer Cells in Part by Bmi1 Downregulation}

Given that HDACi has multiple targets depending on cellular and biological contexts, these observed effects induced by HDACi treatment in tongue cancer cells may be directly or indirectly or even not associated with Bmil repression. To address this, we performed the rescue experiments in vitro by enforced overexpression of Bmil following $\mathrm{NaB}$ pretreatment. The Bmil expression vector ( $\mathrm{pcDNA3}-\mathrm{Bmi1}$ ) was first 


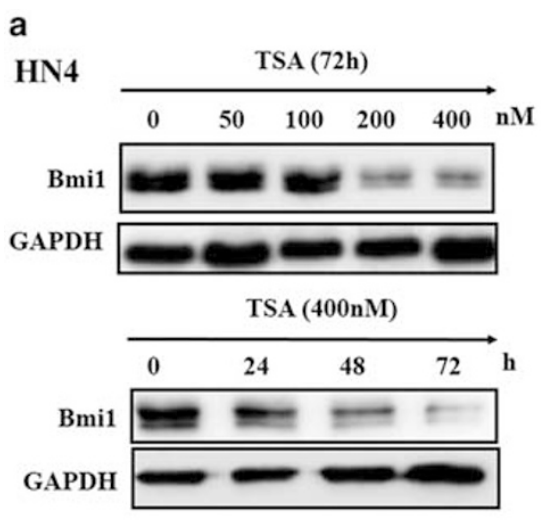

C

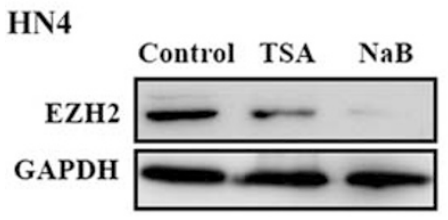

b

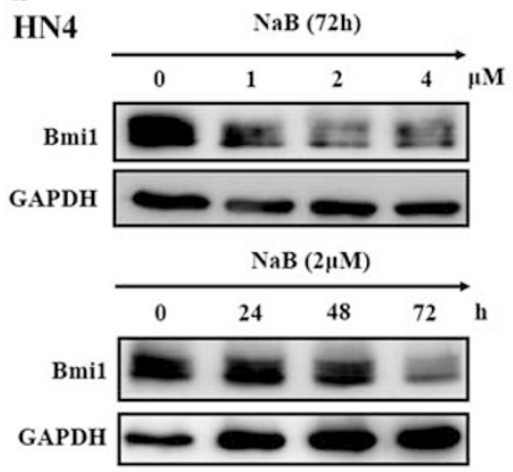

d

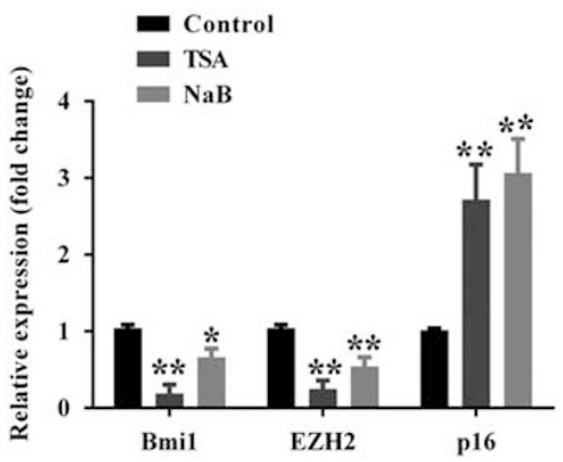

Figure 4 Bmi1 is inhibited by two HDACi in HN4 tongue cancer cells. (a, b) TSA and NaB inhibited Bmi1 in a dose- and time-dependent manner in HN4 cells. Representative images of WB are shown. (c) EZH2 was also inhibited by TSA ( $200 \mathrm{nM})$ and NaB $(2 \mu \mathrm{M})$ in HN4 cells. Representative images of WB are shown. (d) Bmi1, EZH2 and p16 mRNAs were measured by real-time RT-PCR assay after cells were treated with TSA (200 nM) and NaB $(2 \mu \mathrm{M})$ for $48 \mathrm{~h}$. Data shown here are mean \pm s.d. from three independent experiments, ${ }^{*} P<0.05,{ }^{* *} P<0.01$, ANOVA analyses.

verified by transiently delivery into Cal27 cells, which have relative low endogenous Bmil. As shown in Supplementary Figure 6, the abundance of Bmi1 was markedly increased relative to control (pcDNA3-empty). Consistently, the expected changes of $\mathrm{p} 16, \mathrm{E}$-cadherin and Vimentin proteins were observed simultaneously, thus confirming the efficiency of this Bmil expression construct. After pretreated with $\mathrm{NaB}$ $(2 \mu \mathrm{M})$ for $48 \mathrm{~h}$, then these cells received transient transfection with pcDNA3-Bmil or pcDNA3-empty. Following another $48 \mathrm{~h}$ after transfection, these cells were harvested for analyses. As shown in Figure 6a, the pcDNA3-Bmil transfection was capable to partially rescue the Bmil expression after $\mathrm{NaB}$ pretreatment, whereas the empty plasmid failed. More importantly, the effects on cell proliferation, apoptosis and migration induced by $\mathrm{NaB}$ were partially relieved by enforced Bmil overexpression (Figures 6b, c and d). Collectively, our data suggest that these anticancer effects triggered by $\mathrm{NaB}$ on tongue cancer cells were attributed at least in part to Bmil downregulation.

\section{Genetic and Pharmacologic Inhibition of Bmi1 Inhibited Tumor Growth In Vivo}

To further reinforce the notion that Bmil is critical for tongue cancer growth and testify the therapeutic efficiency of
$\mathrm{NaB}$ in vivo, both genetic and pharmacologic approaches were further utilized to inhibit Bmil in a tongue cancer xenograft model. Equal amount of HN4 Bmil-knockdown cells (HN4-shBmil) and control cells (HN4-NC) were transplanted subcutaneously into flanks of nude mice. As shown in Figures $7 \mathrm{a}$ and $\mathrm{b}$, the data indicated that the tumor grew much faster in control cells transplantation as compared with Bmil-knockdown cells transplantation as measured by tumor volume and final tumor weight. Then, we went on to testify the in vivo effects of $\mathrm{NaB}$ in tongue cancer growth. After subcutaneous inoculation of HN4 cells for 4 weeks, tumor masses were established and then mice were randomly grouped for drug treatment ( $\mathrm{NaB}$ or vehicle by intraperitoneal injection). The data derived from tumor volume and weight clearly indicated that $\mathrm{NaB}$ treatment significantly retarded tumor growth, although tumor regression was not achieved (Figures $7 \mathrm{c}$ and $\mathrm{d}$ ). The immunohistochemical staining data displayed remarkably inhibited Bmil expression in NaB-treated samples as compared with vehicle-treated samples (Figure 7e). Together, these findings reveal that Bmil is required for tongue cancer growth in vivo and $\mathrm{NaB}$ treatment impaired tongue cancer growth likely via Bmil inhibition. 
a

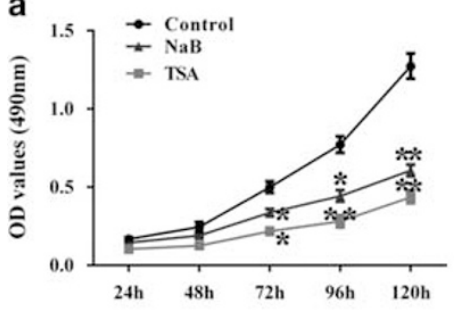

b

C
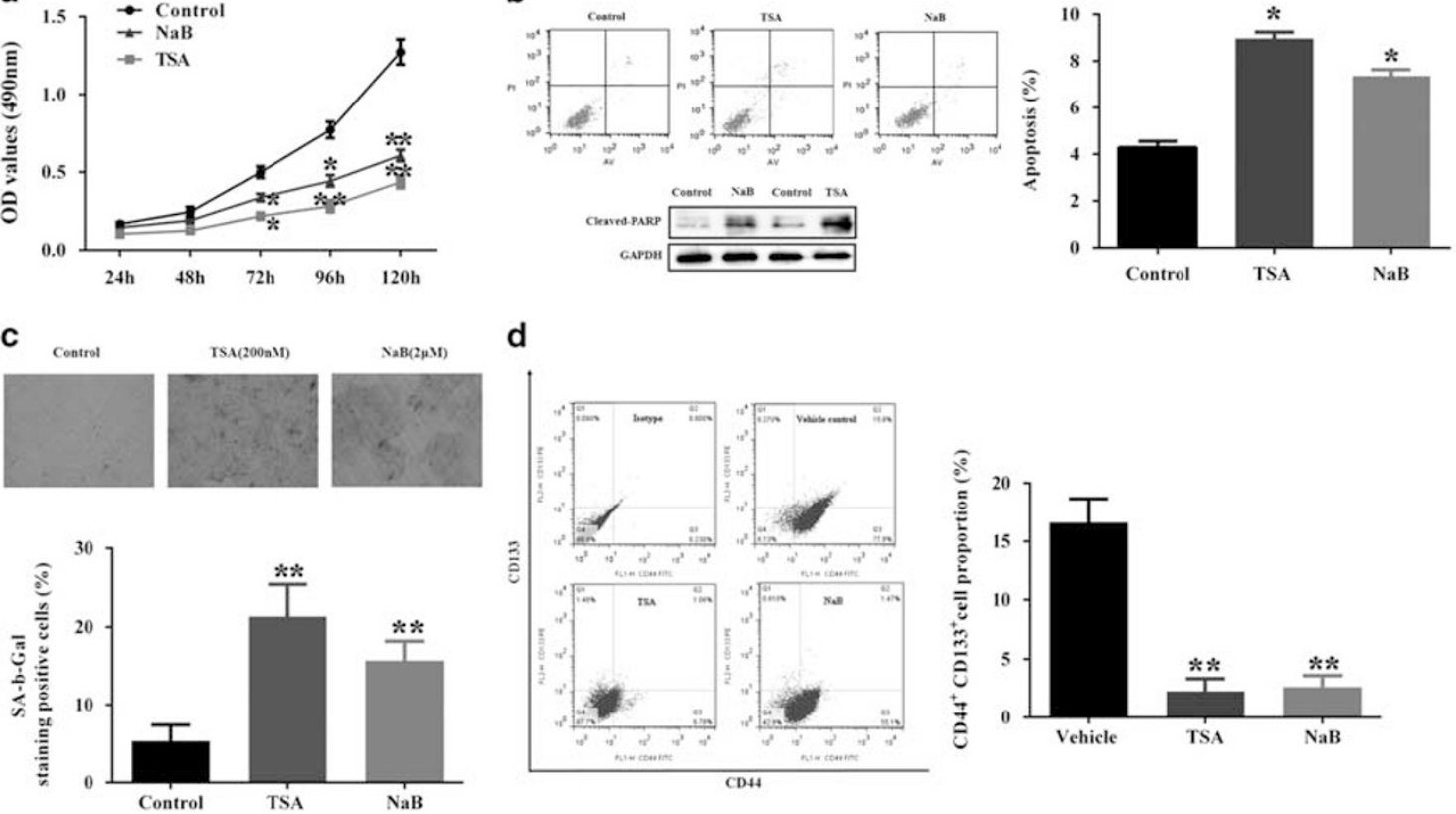

d
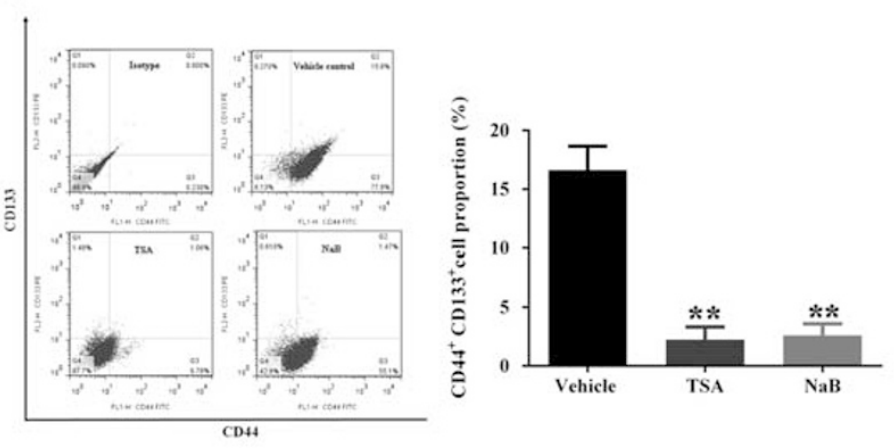

e
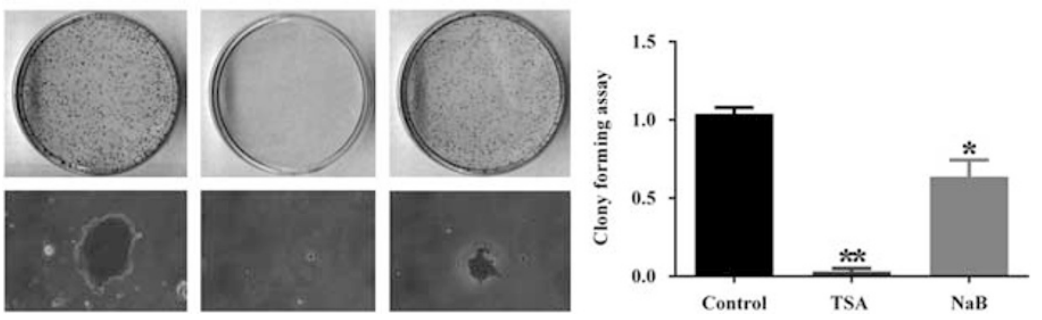

f

Figure 5 The effects of HDACi treatments largely phenocopy Bmi1 knockdown in HN4 tongue cancer cells. (a) Cell proliferation was significantly impaired in HN4 cells after TSA and NaB treatments as measured by MTT assay. (b) The percentages of apoptotic cells were remarkably increased in HN4 cells after TSA and NaB treatments as determined by flow cytometry and cleaved-PARP expression (WB). (c) SA- $\beta$-gal staining positive cells were determined and compared after HN4 cells were treated with TSA and $\mathrm{NaB}$ for $72 \mathrm{~h}$. (d) The percentages of $\mathrm{CD} 44^{+} \mathrm{CD} 133^{+}$sub-population were decreased significantly in TSA or NaB-treated HN4 cells as determined by FACS. (e) The colony formation efficiencies were impaired in HN4 cells in the presence of TSA or NaB. (f) Cell viability and proliferation was determined in HN4 cells treated with TSA/NaB alone or in combination with cisplatin. The dosages of TSA and $\mathrm{NaB}$ used here were $200 \mathrm{nM}$ and $2 \mu \mathrm{M}$ unless other specified. Data shown here are mean \pm s.d. from three independent experiments, ${ }^{*} P<0.05,{ }^{*} P<0.01$, Student's $t$-test and ANOVA analyses.

\section{DISCUSSION}

The polycomb group proteins maintain gene expression by modifying chromatin structure and involve in various fundamental biological processes including stem cell plasticity, cell differentiation and proliferation. ${ }^{5,40}$ Mounting evidence has demonstrated that Bmil, the core component of PRC1, has been increasingly recognized as a key bona fide oncogene underlying tumorigenesis and a potential therapeutic target against human cancer. ${ }^{19}$ In this study, our data reveal that Bmil is abnormally overexpressed in a large fraction of tongue cancers and its overexpression associates with aggressive malignant characteristics and patients outcomes. Moreover, using genetic knockdown and pharmacological approach, multiple oncogenic roles of Bmil were identified in cancer cell proliferation, cellular apoptosis and senescence, and $\mathrm{CD} 44^{+} \mathrm{CD} 133^{+}$sub-population maintenance during tongue cancer progression. HDACs $\mathrm{NaB}$ was capable to induce therapeutic effects on tongue cancer cells presumably through Bmil inhibition both in vitro and in a xenograft animal model.

Accumulating evidence has indicated that Bmil represents an oncogene that was strongly linked to cell transformation, EMT and cancer stem cell propagation in diverse cancer contexts including oral cancers. ${ }^{8,12,41}$ Previous studies have reported that ectopic Bmil overexpression results in senescence bypass and immortalization of normal keratinocytes and associates with malignant progression of precancerous oral lesion into cancers. ${ }^{41,42}$ Moreover, overexpression of Bmil occurred at a very early stage in oral carcinogenesis and was required for cancer cell proliferation and survival..$^{30}$ Our data 

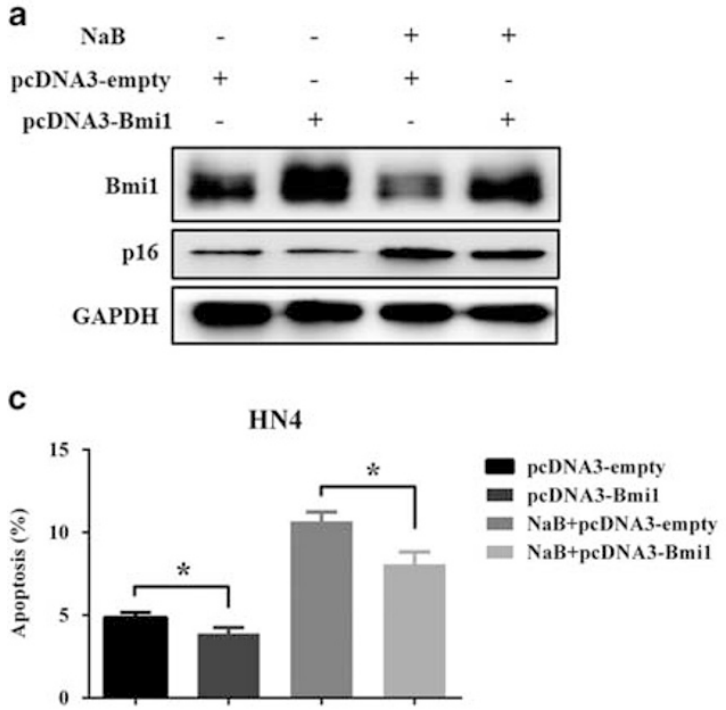

b
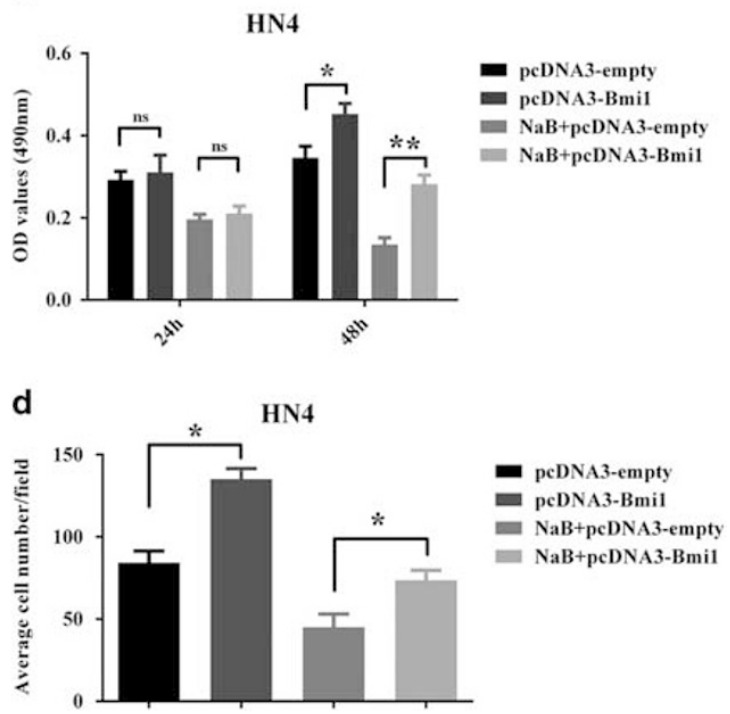

Figure $6 \mathrm{NaB}$ induces therapeutic effects in part via Bmi1 inhibition in tongue cancer cells. (a) Enforced Bmi1 overexpression attenuated Bmi1 inhibition induced by $\mathrm{NaB}$ pretreatment. These cell underwent $\mathrm{NaB}$ exposure for $48 \mathrm{~h}$ and then were transfected with Bmi1 vectors (pcDNA3-Bmi1or empty as control) for another $48 \mathrm{~h}$. The abundance of Bmi1 and its downstream target p16 were measured by WB. Representative images are shown. (b-d) Following $\mathrm{NaB}$ pretreatment for $48 \mathrm{~h}$ and Bmi1 plasmids (pcDNA3-Bmi1 or empty as control) transfection for $48 \mathrm{~h}$, these cells were harvested for cell proliferation (b), apoptosis (c) and migration assay (d). Data shown here are mean \pm s.d. from two independent experiments, NS, nonsignificant, ${ }^{*} P<0.05,{ }^{* *} P<0.01$, Student's $t$-test and ANOVA analyses.
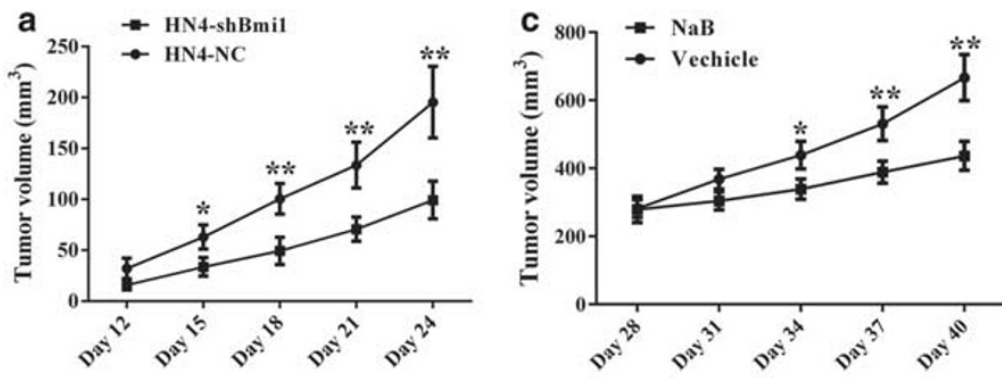

e
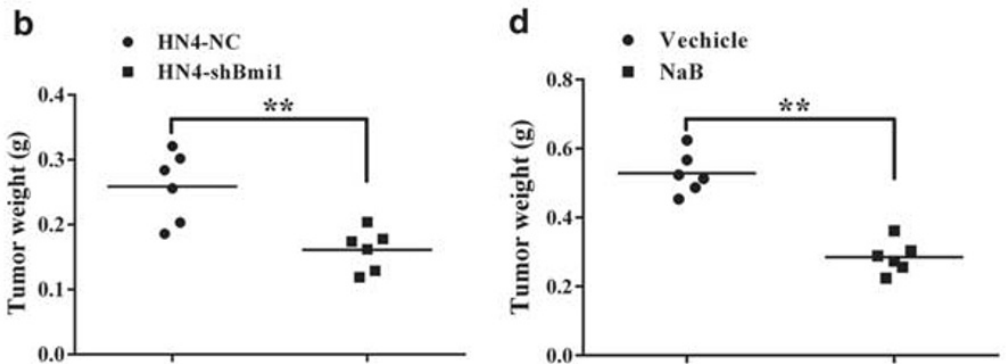

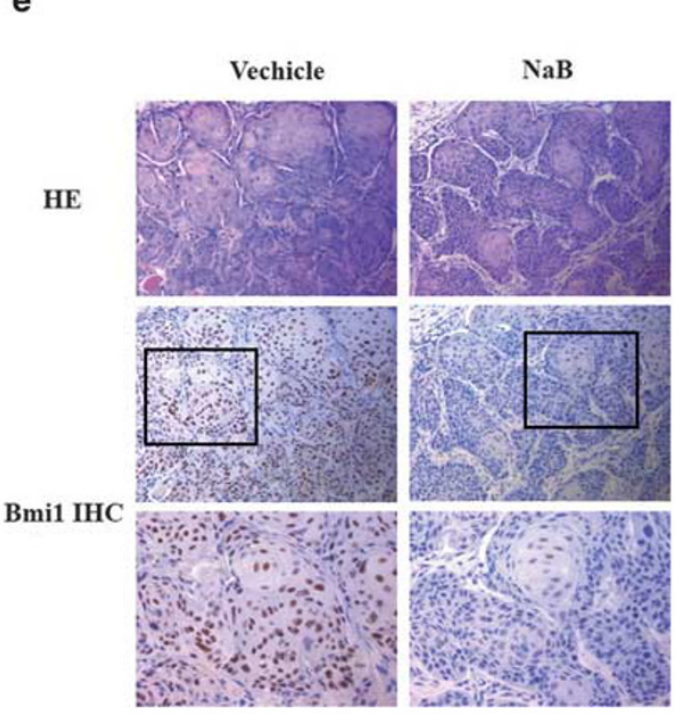

Figure 7 Genetic silencing of Bmi1 or pharmacological inhibition of Bmi1 by NaB impairs tumor growth in a TSCC xenograft model. (a) Volume changes in tumor masses formed from HN4-shBmi1 and HN4-NC cells. (b) Final tumor weight in samples harvested from mice bearing HN4-shBmi1 and HN4-NC cells. (c) Volume changes from two animal groups treated with $\mathrm{NaB}(150 \mathrm{mg} / \mathrm{kg} /$ day) or vehicle (PBS) after tumor masses were established 4 weeks after subcutaneous inoculation. (d) Final tumor weight in samples harvested from mice treated with $\mathrm{NaB}$ ( $150 \mathrm{mg} / \mathrm{kg} / \mathrm{day}$ ) or vehicle (PBS). (e) HE (magnification: $\times 200)$ and immunohistochemical staining (IHC, magnification: $\times 200$ and 400) in two tumor samples from mice treated with NaB $(150 \mathrm{mg} / \mathrm{kg} /$ day) or vehicle (PBS), respectively. Representative images are shown. Images in lower panel (magnification: $\times 400)$ showed the magnification of black-labeled parts in middle panel (magnification: $\times 200$ ). ${ }^{*} P<0.05,{ }^{* *} P<0.01$, Student's $t$-test. 
further revealed aberrant overexpression patterns of Bmil in tongue cancers. Bmil upregulation associated with clinical aggressive features and patient prognosis. However, our finding is inconsistent with a previous study, which revealed that Bmil expression did not correlate with any clinical and histopathological parameters and its negative expression may serve as a poor prognostic marker in patients with primary T1N0M0 tongue cancers. ${ }^{26}$ We reasoned that such discrepancy may be partially due to different patient's inclusion criteria, sample volume and immunohistochemical scoring protocol. Therefore, our results together with most previous studies indicate that aberrant Bmil overexpression may be one of the pivotal molecular events during tongue tumorigenesis and also a novel biomarker for tongue cancer with diagnostic and prognostic significance.

The clinicopathological significance of Bmil overexpression in tongue cancers prompted us to further dissect the biological roles of Bmil during cancer progression by loss-of-function assay using genetic knockdown in vitro and in vivo. Our data reveal that Bmil regulates cell proliferation, cell apoptosis and senescence, and cell motility in tongue cancer cells, which generally agree with the previously reported oncogenic functions of Bmil in diverse human cancers. ${ }^{5,19}$ A line of evidence has established that Bmil has multiple tumorigenic roles in cancer progression by regulating a myriad of target genes. We believe that these well-established downstream targets such as p16, p14 and E-cadherin are largely responsible for Bmil-mediated phenotypes in tongue cancer. For example, derepressed p16 and p14 following endogenous Bmil silencing presumably accounted for impaired cell proliferation and cellular senescence induction, because the well-known functions of p16 and p14 involved in cell cycle progression and premature senescence have long appreciated. ${ }^{18,19,43}$ The close correlation between Bmil and Ki-67 expression in clinical samples also supported the proproliferative roles of Bmil conferred on tongue cancer cells. The in vivo data from xenograft animal model provided further evidence that Bmil is required and critical for tongue cancer growth.

Bmil has critical roles implicated in normal and malignant stem cell self-renewal and maintenance in several tissues. ${ }^{7,13}$ In particular, Bmil was recently identified as a key marker of lingual epithelial stem cells, which were important for tissue maintenance and regeneration of lingual epithelium. ${ }^{44}$ This unique cell sub-population with tumor-initiating properties, termed cancer stem cells, is phenotypically identified in head neck cancers with cell surface markers CD44, CD133 or ALDH1 and thought to be critically responsible for cancer initiation, progression and therapeutic resistance. ${ }^{45}$ For example, Bmil was highly enriched in $\mathrm{CD}_{133^{+}}$laryngeal cancer stem cells and critically required for their proliferation and expansion. ${ }^{46}$ Properties of cancer stem cell in human colorectal cancer are highly dependent on Bmil, because downregulation of Bmil inhibits their self-renewal and abrogates their tumorigenic potential in vitro and in animal models. ${ }^{20}$ Not surprisingly, consistent with these findings,
Bmil was found significantly enriched in $\mathrm{CD} 44^{+} \mathrm{CD} 133^{+}$ sub-population containing cancer stem cell from tongue cancer lines. Bmil depletion inhibited colony formation, reduced the percentage of cancer stem cell population with accompanying downregulation of CD44 and CD133. Moreover, these Bmil-depleted cell appeared to be more vulnerable to conventional anticancer agent cisplatin and displayed significantly impaired proliferation. These data strongly suggest that Bmil may be indispensable for cancer stem cell maintenance and implicated in cisplatin-related chemoresistance in tongue cancer. However, further in-depth investigations into the molecular roles of Bmil in tongue cancer stem cell homeostasis are warranted.

Recently, it has been reported that the HDACi inhibited the core members of polycomb group proteins, Bmil and EZH2 in particular, in multiple cancer contexts. ${ }^{23,25}$ Specifically, HDACi can downregulate the expression of Bmil by transcriptional mechanism in breast cancer cells. ${ }^{23}$ Bmil was also significantly repressed by diverse HDACi chemical inhibitors during mesenchymal stem cell senescence and phenotypic alternation of cancer stem cells derived from head neck cancers. ${ }^{24,47}$ Thus, these findings suggested that Bmil can be robustly inhibited by HDACi in different biological contexts and offered some valuable clues that HDACi chemical compounds may have anticancer properties by suppressing Bmil in addition to other known targets and molecular pathways. In agreement with these, our results clearly indicate that Bmil is potently inhibited by two different HDACi in tongue cancer cells in vitro. Furthermore, this inhibition may be attributed to transcriptional repression induced by $\mathrm{HDACi}$, because we reasoned that increased acetylation of core histone resulting from HDACi impaired transcription factor accessibility and function, thereby favoring gene silencing. ${ }^{48}$ The decreased mRNAs of Bmil upon HDACi treatment also supported this notion. Of course, here we cannot rule out the possibility that Bmil inhibition may be indirectly induced by HDACi besides transcriptional silencing and other mediators exist for HDACi anticancer functions, which is needed to further clarified and confirmed. Generally, similar with the effects induced by HDACi in other cancers, these chemical compounds impaired cell growth as well as induced cell apoptosis and senescence in tongue cancer. $^{49,50}$ Moreover, HDACi exposure also significantly reduced cell colony formation and $\mathrm{CD} 44^{+} \mathrm{CD} 133^{+}$cell fraction, and enhanced cisplatin sensitivity in tongue cancer cells. These phenotypic alternations induced by HDACi largely phenocopied the Bmil knockdown. Moreover, our in vitro rescue experiments indicate that ectopic Bmil overexpression was capable to attenuate the repression of Bmil induced by $\mathrm{NaB}$ exposure and partially attenuate the resulting phenotypic changes after $\mathrm{NaB}$ treatment. These findings support the idea that the therapeutic effects of HDACi $\mathrm{NaB}$ were as least in part due to its inhibition of Bmil. Cancer stem cell sub-population in tongue cancer may be efficiently targeted by HDACi, which is quite beneficial to 
reduce disease recurrence and therapeutic resistance. Our findings from the xenograft animal model showed that $\mathrm{NaB}$ treatment alone significantly inhibited tumor growth, thus offering valuable clues to further determine the therapeutic efficiency of HDACi alone or in combination with conventional agents to eradicate tongue cancers.

Previous studies have indicated that HDACi treatment have the capacities to both inhibit and induce EMT program in diverse cell types and biological contexts. ${ }^{51-54}$ On the one hand, HDACi chemicals reverted the mesenchymal phenotype by inducing E-cadherin gain and vimentin loss in gefitinib-resistant $\mathrm{KB}$ and Hep-2 cell undergoing EMT and murine hepatocytes with TGF- $\beta 1$-induced EMT. ${ }^{53,54}$ However, on the other hand, some HDACi unexpectedly triggered EMT program via Snail upregulation in human nasopharyngeal carcinoma cell lines CNE2 and HepG2, and head neck cancer cell lines HN6 and HN13, ${ }^{52,55}$ In our study, TSA appeared to paradoxically induce EMT-like changes such as morphological alternation, E-cadherin gain and vimentin loss and enhanced cell motility in tongue cancer cell lines, whereas $\mathrm{NaB}$ had no such unexpected capabilities. These findings raise the possibility that some other uncharacterized targets of HDACi independent of Bmil may be responsible for these contradictory EMT changes. It will be interesting to further comprehensively dissect the anticancer functions of diverse HDACi, which is an essential prerequisite before these chemicals were translated into the clinic.

In this study, our findings indicate that Bmil serves as a key driver with multiple oncogenic functions during tongue cancer progression and as a novel biomarker for diagnosis and prognostic prediction for patients. HDACi chemicals such as $\mathrm{NaB}$ induce therapeutic effects against tongue cancer probably in part by Bmil repression. We anticipate that pharmacological and genetic disruption of Bmil may represent a novel therapeutic strategy against tongue cancers.

Supplementary Information accompanies the paper on the Laboratory Investigation website (http://www.laboratoryinvestigation.org)

\section{ACKNOWLEDGMENTS}

We thank Dr Liang-Nian Song (Herbert Irving Comprehensive Cancer Center, Columbia University) for critical review and helpful discussion of the manuscript. We are grateful to Professor Wantao Chen for providing cell lines and Professor Muh-Hwa Yang for kind gift of Bmi1 plasmids. This work was supported, in whole or in part, by National Natural Science Foundation of China (Grant no. 81100737), Natural Science Foundation of Jiangsu Province (Grant no. BK2011762, BK20130898), Specialized Research Fund for the Doctoral Program of Higher Education (Grant no. 20113234120003), A Project Funded by the Priority Academic Program Development of Jiangsu Higher Education Institutions (Grant no. 2014-37, JX10531802), and China Postdoctoral Science Foundation (2014M560436).

\section{DISCLOSURE/CONFLICT OF INTEREST}

The authors declare no conflict of interest.
1. Haddad RI, Shin DM. Recent advances in head and neck cancer. N Engl J Med 2008;359:1143-1154.

2. Ferlay J, Shin HR, Bray F, et al. Estimates of worldwide burden of cancer in 2008: GLOBOCAN 2008. Int J Cancer 2010;127:2893-2917.

3. Siegel R, DeSantis $C$, Virgo $K$, et al. Cancer treatment and survivorship statistics, 2012. CA Cancer J Clin 2012;62:220-241.

4. Scully C, Bagan JV. Recent advances in oral oncology 2008; squamous cell carcinoma imaging, treatment, prognostication and treatment outcomes. Oral Oncol 2009;45:e25-e30.

5. Sauvageau M, Sauvageau G. Polycomb group proteins: multi-faceted regulators of somatic stem cells and cancer. Cell Stem Cell 2010;7: 299-313.

6. Jacobs JJ, Kieboom K, Marino S, et al. The oncogene and polycombgroup gene bmi-1 regulates cell proliferation and senescence through the ink4a locus. Nature 1999;397:164-168.

7. Lukacs RU, Memarzadeh $\mathrm{S}, \mathrm{Wu} \mathrm{H}$, et al. Bmi-1 is a crucial regulator of prostate stem cell self-renewal and malignant transformation. Cell Stem Cell 2010;7:682-693.

8. Yang MH, Hsu DS, Wang HW, et al. Bmi1 is essential in Twist1-induced epithelial-mesenchymal transition. Nat Cell Biol 2010;12:982-992.

9. Song LB, Zeng MS, Liao WT, et al. Bmi-1 is a novel molecular marker of nasopharyngeal carcinoma progression and immortalizes primary human nasopharyngeal epithelial cells. Cancer Res 2006;66: 6225-6232.

10. Mohty M, Yong AS, Szydlo RM, et al. The polycomb group BMl1 gene is a molecular marker for predicting prognosis of chronic myeloid leukemia. Blood 2007;110:380-383.

11. Guo BH, Feng $\mathrm{Y}$, Zhang $\mathrm{R}$, et al. Bmi-1 promotes invasion and metastasis, and its elevated expression is correlated with an advanced stage of breast cancer. Mol Cancer 2011;10:10.

12. Dovey JS, Zacharek SJ, Kim CF, et al. Bmi1 is critical for lung tumorigenesis and bronchioalveolar stem cell expansion. Proc Natl Acad Sci USA 2008;105:11857-11862.

13. Gargiulo $G$, Cesaroni $M$, Serresi $M$, et al. In vivo RNAi screen for BMl1 targets identifies TGF-beta/BMP-ER stress pathways as key regulators of neural- and malignant glioma-stem cell homeostasis. Cancer Cell 2013:23:660-676.

14. Meng $X$, Wang $Y$, Zheng $X$, et al. shRNA-mediated knockdown of Bmi-1 inhibit lung adenocarcinoma cell migration and metastasis. Lung Cancer 2012;77:24-30.

15. Wu Z, Min L, Chen D, et al. Overexpression of BMI-1 promotes cell growth and resistance to cisplatin treatment in osteosarcoma. PLoS One 2011;6:e14648.

16. Smith LL, Yeung J, Zeisig BB, et al. Functional crosstalk between Bmi1 and MLL/Hoxa9 axis in establishment of normal hematopoietic and leukemic stem cells. Cell Stem Cell 2011;8:649-662.

17. Chiba T, Miyagi S, Saraya A, et al. The polycomb gene product BMI1 contributes to the maintenance of tumor-initiating side population cells in hepatocellular carcinoma. Cancer Res 2008;68:7742-7749.

18. Bennecke $M$, Kriegl L, Bajbouj $M$, et al. Ink4a/Arf and oncogeneinduced senescence prevent tumor progression during alternative colorectal tumorigenesis. Cancer Cell 2010;18:135-146.

19. Cao L, Bombard J, Cintron K, et al. BMI1 as a novel target for drug discovery in cancer. J Cell Biochem 2011;112:2729-2741.

20. Kreso A, van Galen P, Pedley NM, et al. Self-renewal as a therapeutic target in human colorectal cancer. Nat Med 2014;20:29-36.

21. West AC, Johnstone RW. New and emerging HDAC inhibitors for cancer treatment. J Clin Invest 2014;124:30-39.

22. Iglesias-Linares A, Yanez-Vico RM, Gonzalez-Moles MA. Potential role of HDAC inhibitors in cancer therapy: insights into oral squamous cell carcinoma. Oral Oncol 2010;46:323-329.

23. Bommi PV, Dimri M, Sahasrabuddhe AA, et al. The polycomb group protein BMI1 is a transcriptional target of HDAC inhibitors. Cell Cycle 2010;9:2663-2673.

24. Jung JW, Lee S, Seo MS, et al. Histone deacetylase controls adult stem cell aging by balancing the expression of polycomb genes and jumonji domain containing 3. Cell Mol Life Sci 2010;67:1165-1176.

25. Romanski A, Schwarz $K$, Keller $M$, et al. Deacetylase inhibitors modulate proliferation and self-renewal properties of leukemic stem and progenitor cells. Cell Cycle 2012;11:3219-3226.

26. Hayry V, Makinen LK, Atula $\mathrm{T}$, et al. Bmi-1 expression predicts prognosis in squamous cell carcinoma of the tongue. $\mathrm{Br} J$ Cancer 2010;102:892-897. 
27. Chen H, Zhou L, Wan G, et al. BMl1 promotes the progression of laryngeal squamous cell carcinoma. Oral Oncol 2011;47:472-481.

28. Chou CH, Yang NK, Liu TY, et al. Chromosome instability modulated by BMI1-AURKA signaling drives progression in head and neck cancer. Cancer Res 2013;73:953-966.

29. Song LB, Li J, Liao WT, et al. The polycomb group protein Bmirepresses the tumor suppressor PTEN and induces epithelialmesenchymal transition in human nasopharyngeal epithelial cells. J Clin Invest 2009;119:3626-3636.

30. Kang MK, Kim RH, Kim SJ, et al. Elevated Bmi-1 expression is associated with dysplastic cell transformation during oral carcinogenesis and is required for cancer cell replication and survival. Br J Cancer 2007; 96:126-133.

31. Wang C, Liu X, Chen Z, et al. Polycomb group protein EZH2-mediated $\mathrm{E}$-cadherin repression promotes metastasis of oral tongue squamous cell carcinoma. Mol Carcinog 2013;52:229-236.

32. Douglas $\mathrm{D}, \mathrm{Hsu} \mathrm{JH}$, Hung $\mathrm{L}$, et al. BMI-1 promotes ewing sarcoma tumorigenicity independent of CDKN2A repression. Cancer Res 2008;68:6507-6515.

33. Li Z, Wang Y, Qiu J, et al. The polycomb group protein EZH2 is a novel therapeutic target in tongue cancer. Oncotarget 2013;4:2532-2549.

34. Wei Z, Wang Y, Li Z, et al. Overexpression of Hippo pathway effector TAZ in tongue squamous cell carcinoma: correlation with clinicopathological features and patients' prognosis. J Oral Pathol Med 2013:42:747-754

35. Liu LK, Jiang XY, Zhou XX, et al. Upregulation of vimentin and aberrant expression of E-cadherin/beta-catenin complex in oral squamous cell carcinomas: correlation with the clinicopathological features and patient outcome. Mod Pathol 2010;23:213-224.

36. Siddique HR, Saleem M. Role of BMI1, a stem cell factor, in cancer recurrence and chemoresistance: preclinical and clinical evidences. Stem Cells 2012;30:372-378.

37. Prince $M E$, Sivanandan $R$, Kaczorowski $A$, et al. Identification of a subpopulation of cells with cancer stem cell properties in head and neck squamous cell carcinoma. Proc Natl Acad Sci USA 2007;104: 973-978.

38. Sinha N, Mukhopadhyay S, Das DN, et al. Relevance of cancer initiating/stem cells in carcinogenesis and therapy resistance in oral cancer. Oral Oncol 2013;49:854-862.

39. Park IK, Morrison SJ, Clarke MF. Bmi1, stem cells, and senescence regulation. J Clin Invest 2004;113:175-179.

40. Simon JA, Kingston RE. Mechanisms of polycomb gene silencing: knowns and unknowns. Nat Rev Mol Cell Biol 2009;10:697-708.

41. Liu W, Feng JQ, Shen XM, et al. Two stem cell markers, ATP-binding cassette, G2 subfamily (ABCG2) and BMI-1, predict the transformation of oral leukoplakia to cancer: a long-term follow-up study. Cancer 2012;118:1693-1700.

42. Qiao B, Chen Z, Hu F, et al. BMI-1 activation is crucial in hTERT-induced epithelial-mesenchymal transition of oral epithelial cells. Exp Mol Pathol 2013;95:57-61.

43. Rayess H, Wang MB, Srivatsan ES. Cellular senescence and tumor suppressor gene p16. Int J Cancer 2012;130:1715-1725.

44. Tanaka T, Komai Y, Tokuyama Y, et al. Identification of stem cells that maintain and regenerate lingual keratinized epithelial cells. Nat Cell Biol 2013;15:511-518.

45. Gonzalez-Moles MA, Scully C, Ruiz-Avila I, et al. The cancer stem cell hypothesis applied to oral carcinoma. Oral Oncol 2013;49:738-746.

46. Chen H, Zhou L, Dou T, et al. BMI1'S maintenance of the proliferative capacity of laryngeal cancer stem cells. Head Neck 2011:33:1115-1125.

47. Chikamatsu K, Ishii H, Murata T, et al. Alteration of cancer stem cell-like phenotype by histone deacetylase inhibitors in squamous cell carcinoma of the head and neck. Cancer Sci 2013;104:1468-1475.

48. Chi P, Allis CD, Wang GG. Covalent histone modifications-miswritten misinterpreted and mis-erased in human cancers. Nat Rev Cancer 2010;10:457-469.

49. Nagumo T, Takaoka S, Yoshiba $\mathrm{S}$, et al. Antitumor activity of suberoylanilide hydroxamic acid against human oral squamous cell carcinoma cell lines in vitro and in vivo. Oral Oncol 2009;45:766-770.

50. Prystowsky MB, Adomako A, Smith RV, et al. The histone deacetylase inhibitor LBH589 inhibits expression of mitotic genes causing G2/M arrest and cell death in head and neck squamous cell carcinoma cell lines. J Pathol 2009;218:467-477.

51. Kong D, Ahmad A, Bao B, et al. Histone deacetylase inhibitors induce epithelial-to-mesenchymal transition in prostate cancer cells. PLoS One 2012;7:e45045.

52. Giudice FS, Pinto Jr. DS, Nor JE, et al. Inhibition of histone deacetylase impacts cancer stem cells and induces epithelial-mesenchyme transition of head and neck cancer. PLoS One 2013;8:e58672.

53. Bruzzese $F$, Leone $A$, Rocco $M$, et al. HDAC inhibitor vorinostat enhances the antitumor effect of gefitinib in squamous cell carcinoma of head and neck by modulating ErbB receptor expression and reverting EMT. J Cell Physiol 2011;226:2378-2390.

54. Yoshikawa M, Hishikawa K, Marumo $\mathrm{T}$, et al. Inhibition of histone deacetylase activity suppresses epithelial-to-mesenchymal transition induced by TGF-beta1 in human renal epithelial cells. J Am Soc Nephrol 2007;18:58-65.

55. Jiang GM, Wang HS, Zhang $F$, et al. Histone deacetylase inhibitor induction of epithelial-mesenchymal transitions via up-regulation of Snail facilitates cancer progression. Biochim Biophys Acta 2013; 1833:663-671. 